\title{
Ezio Ornato, Libri e colofoni: qualche considerazione- Idem, Tra ostentazione e reticenza. I colofoni nel libro a stampa
}

\section{Gianni Mombello}

\section{(2) OpenEdition Journals}

Édition électronique

URL : http://journals.openedition.org/studifrancesi/34328

DOI : 10.4000/studifrancesi.34328

ISSN : 2421-5856

Éditeur

Rosenberg \& Sellier

\section{Édition imprimée}

Date de publication : 1 novembre 2005

Pagination : 390

ISSN : 0039-2944

\section{Référence électronique}

Gianni Mombello, «Ezio Ornato, Libri e colofoni: qualche considerazione - Idem, Tra ostentazione e reticenza. I colofoni nel libro a stampa », Studi Francesi [En ligne], 146 (XLIX | II) | 2005, mis en ligne le 30 novembre 2015, consulté le 22 avril 2021. URL : http://journals.openedition.org/studifrancesi/34328 ; DOI : https://doi.org/10.4000/studifrancesi.34328

Ce document a été généré automatiquement le 22 avril 2021.

\section{cc) $(9)$}

Studi Francesi è distribuita con Licenza Creative Commons Attribuzione - Non commerciale - Non opere derivate 4.0 Internazionale. 


\title{
Ezio Ornato, Libri e colofoni: qualche considerazione - Idem, Tra ostentazione e reticenza. I colofoni nel libro a stampa
}

\author{
Gianni Mombello
}

\section{RÉFÉRENCE}

EZIO ORNATO, Libri e colofoni: qualche considerazione, «Gazette du livre médiéval», 42, printemps 2003, pp. 24-35. IDEM, Tra ostentazione e reticenza. I colofoni nel libro a stampa, «Gazette du livre médiéval», 43, automne 2003, pp. 34-46.

$1 \quad$ Le premier article contient une analyse détaillée des raisons qui auraient pu pousser les scribes du bas Moyen Age, actifs dans l'Europe occidentale (péninsule ibérique exclue), à dater et/ou signer leurs produits.

2 En ce qui concerne le $\mathrm{XV}^{\mathrm{e}}$ siècle, les manuscrits non datés ni signés constituent encore la grande majorité des cas $(76,93 \%)$, tandis que ceux qui sont datés et non signés $(7,94 \%)$, ou signés et non datés $(9,41 \%)$ s'équivalent et les datés et signés $(5,73 \%)$ restent une nette minorité.

3 La diffusion du colophon aurait pu trouver une des raisons de s'imposer dans l'imitation de l'activité notariale, mais c'est là seulement une des raisons possibles, ainsi que la décadence de l'Université, dont le marché libraire était dominé par la «pecia» anonyme.

De toute manière, les subscriptions augmentent de siècle en siècle. La moyenne européenne (pays ibériques exclus) passe en effet de $25,12 \%$ du XIII ${ }^{e}$ siècle, à $33,39 \%$ pour le $\mathrm{XIV}^{\mathrm{e}}$ siècle et à $49,66 \%$ au $\mathrm{XV}^{\mathrm{e}}$ siècle. Dans ce contexte, deux vastes zones s'opposent, tout en aboutissant pareillement à la généralisation du colophon: les pays 
germaniques et l'Italie. Les premiers produisent surtout de médiocres manuscrits sur papier et on sait que les manuscrits sur papier révèlent un taux de subscription plus élevé. En Italie, le copiste humaniste, qui possède un niveau culturel supérieur à celui de son commanditaire éventuel, essaie de sortir de l'anonymat. La France, qui continua à produire des manuscrits sur parchemin, constitue un cas à part.

On aimerait bien en savoir davantage sur les pays soumis aux ducs de la dernière maison de Bourgogne, qui ont formé, pour un laps de temps assez long, une unité politique et culturelle remarquable caractérisée par l'activité d'ateliers importants et assez bien identifiés. De même, il serait intéressant de savoir si les scribes qui ont produit des livres en latin et/ou dans les langues vernaculaires ont suivi les mêmes consuétudes en ce qui concerne le colophon; et qu'en est-il des manuscrits dus à plusieurs scribes? Que de recherches encore à faire!

6 Le deuxième article prend en considération la présence ou l'absence du colophon dans ses trois éléments constitutifs (date, lieu, imprimeur-libraire), ce qui synthétise bien le «rapporto di rottura» existant entre les exigences qui présidaient à la fabrication de manuscrits et à la production de livres imprimés avant 1501. Cette différence est saisie d'un point de vue adroitement choisi.

7 Un bon produit imprimé exige la 'griffe', d'où un taux relativement élevé de présence d'un colophon qui permet de constater, entre autres, si, dans une ville ou région donnée, cette production est en hausse ou en baisse quantitative et/ou surtout qualitative. Les copistes de manuscrits avaient été moins sensibles à cette exigence qui trouve sa raison d'être dans les lois d'un marché qui devenait de plus en plus vaste.

Contributions fort intéressantes par un maître de la bibliographie quantitative. 